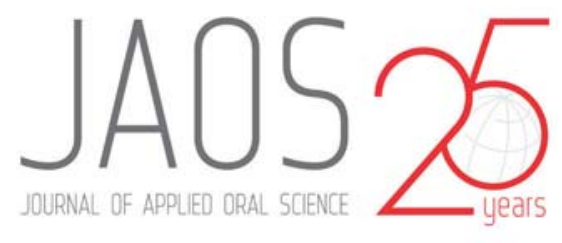

\title{
Investigations of the prevalence and virulence of Candida albicans in periodontal and endodontic lesions in diabetic and normoglycemic patients
}

\section{Abstract}

Cinthya Cristina GOMES ${ }^{1}$

Ludmila Silva GUIMARÃES 2

Larissa Christina Costa PINTO²

Gabriela Alessandra da

Cruz Galhardo CAMARGO1

Maria Isabel Bastos VALENTE1

Maria Inêz de Moura SARQUIS ${ }^{3}$
Submitted: August 24, 2016 Modification: November 11, 2016 Accepted: December 29, 2016
Pulpal and periodontal tissues have similar microbiota that allows crosscontamination between the pulp and periodontal tissues. Objective: The aim of this study was to investigate the prevalence of isolated Candida albicans from periodontal endodontic lesions in diabetic and normoglycemic patients, and the fungi's virulence in different atmospheric conditions. Material and Methods: A case-control study was conducted on 15 patients with type 2 diabetes mellitus (G1) and 15 non-diabetics (G2) with periodontal endodontic lesions. Samples of root canals and periodontal pockets were plated on CHROMagar for later identification by polymerase chain reaction (PCR) and virulence test. Results: C. albicans was identified in $79.2 \%$ and $20.8 \%$ of the 60 samples collected from diabetic and normoglycemic patients, respectively. Of the 30 samples collected from periodontal pockets, 13 showed a positive culture for C. albicans, with $77 \%$ belonging to $\mathrm{G} 1$ and $23 \%$ to G2. Of the 11 positive samples from root canals, $82 \%$ were from G1 and $18 \%$ from G2. Production of proteinase presented a precipitation zone $\mathrm{Pz}<0.63$ of $100 \%$ in $\mathrm{G} 1$ and $72 \%$ in $\mathrm{G} 2$, in redox and negative $(P z=1)$, under anaerobic conditions in both groups. Hydrophobicity of the strains from G1 indicated $16.4 \%$ with low, $19.3 \%$ with moderate, and $64.3 \%$ with high hydrophobicity in redox. In G2, 42.2\% had low, 39.8\% had moderate, $18 \%$ had high hydrophobicity in redox. In anaerobic conditions, G1 showed $15.2 \%$ with low, $12.8 \%$ with moderate, and $72 \%$ with high hydrophobicity; in G2, 33.6\% had low, $28.8 \%$ had moderate, and $37.6 \%$ had high hydrophobicity. There was statistical difference in the number of positive cultures between $G 1$ and $G 2(p<0.05)$ with predominance in G1. There was statistical difference for all virulence factors, except hemolysis $(p=0.001)$. Conclusions: Candida albicans was isolated more frequently and had higher virulence in diabetic patients.

Keywords: I nfection. Candida albicans. Diabetes mellitus.
Corresponding address: Cinthya Cristina Gomes Departamento de Formação Específica Faculdade de Odontologia de Nova Friburgo Universidade Federal Fluminense Rua Doutor Silvio Henrique Braune, 22 - Centro Nova Friburgo - RJ - Brazil - 28625-650 e-mail: cinthyagomes@id.uff.br
${ }^{U}$ Universidade Federal Fluminense, Faculdade de Odontologia, Departamento de Formação Específica, Nova Friburgo, RJ, Brasil.

Universidade Federal Fluminense, Faculdade de Odontologia, Programa de Pós-graduação em Odontologia, Nova Friburgo, RJ, Brasil.

${ }^{3}$ Instituto Osvaldo Cruz, Departamento de Micologia, Laboratório de Taxonomia, Bioquímica e Prospecção de Fungos, Rio de Janeiro, RJ, Brasil. 


\section{Introduction}

Combined periodontal/endodontic lesions have been characterized as infectious processes that occur simultaneously in the pulp and the periodontal tissue of the same tooth ${ }^{1}$.

Dental pulp and periodontal tissues have similarities regarding microbiota and fungi infections in root canals and advanced periodontitis ${ }^{7,9}$. In the oral cavity, fungi can be isolated from mucosal surfaces, however, it can also be found in biofilm, root canal infections, periimplant lesions, and periodontal pockets ${ }^{24}$. Candida albicans is a commonly identified species of fungi and has higher prevalence in saliva and in the root canal ${ }^{6}$. It is considered an opportunist microorganism found not only in teeth with pulp necrosis and apical periodontitis ${ }^{8}$, but also in periodontal pockets, suggesting that it may be involved in the pathogenesis of periodontal disease $^{5}$. Candida in the oral cavities could facilitate the increase of pathogenic microorganisms as it modifies the host defense mechanism. There is a correlation between increased incidence of infections caused by fungi and immunocompromised patients, including patients with hematological diseases, AIDS, diabetes mellitus, broad spectrum antibiotics users, and those that use steroids in high doses $5,8,24$.

Diabetes mellitus is a chronic disease that may reduce resistance to microbial infection of tissues and decrease tissue repair capacity ${ }^{27}$. It is both an endocrine and a metabolic dysfunction involving the control of blood glucose levels, resulting in hyperglycemia. Chronic hyperglycemia may trigger deficiencies in the immune system, increasing the risk of infections, including in the oral cavity ${ }^{14,15}$

An association between diabetes and periodontal disease has been well documented and poor glycemic control may lead to increased severity of periodontitis ${ }^{14}$. A bidirectional relationship between diabetes mellitus and periodontal diseases has been discussed. It is estimated that patients with poor glycemic control are three times more likely to develop periodontal destruction compared to normoglycemic individuals ${ }^{14}$. However, the literature on pathogenesis, progression, and endodontic treatment of pathologies in diabetic patients is extremely sparse ${ }^{7}$.

Candida species possess multiple virulence factors that help in the invasion of the host tissue and evasion of host defence mechanisms. Such factors include hydrolitic enzymes production, hydrophobic interaction, hemolytic activity. The hydrolytic enzymes include secreted aspartyl proteinase (SAP) and phospholipase that cause the inhibition of fagocitosis processes by degrading immunoglobulins and extracellular matrix proteins ${ }^{18}$. Hydrophobic interaction play an important role in the adherence of pathogenic microorganisms to host cells by facilitating contact between the parasite and host cell ${ }^{19}$. Hemolysin activity, followed by iron acquisition, is considered an important virulence attribute of Candida species. Iron is used by the fungus for metabolism, growth and for facilitating hyphal invasion during host infection ${ }^{17}$. The hemolysin activity of $\mathrm{C}$. albicans in diabetic patients may be directly or indirectly increased in the presence of high glucose concentration in the blood ${ }^{25}$.

The aim of this study was to assess the prevalence of Candida albicans isolated from periodontal endodontic lesions of diabetic and nondiabetic patients. Additionally, some virulence factors of Candida albicans were evaluated, such as activity of the proteinase, phospholipase, and hemolysin, and hydrophobicity in a reduced oxygen atmosphere or in anaerobic conditions.

\section{Material and methods}

This research was approved and is in accordance with the Ethical Committee for Research through the document CEP number 125.285, CAAE number 04247712.3.0000.5243 and Clinical Trials identification NCT02867254. All procedures performed in this study were in accordance with the 1964 Helsinki declaration. Additional informed consent was signed by all participants for whom identifying information is included in this paper. This case-control study was conducted on thirty patients (15 patients with type 2 diabetes mellitus and 15 normoglycemics) with clinical and radiographic diagnosis of a periodontal endodontic lesion. To assess the glycemic control of the patients, plasma glucose level and glycosylated hemoglobin concentrations ( $\mathrm{HbAlc}$ ) were measured. Plasma glucose levels of each patient at the moment of sampling was not estimated. The diabetes diagnosis was performed according to the Guidelines of The American Diabetes Association, which recommends the measurement of plasma glucose and glycosylated hemoglobin level concentrations ( $\mathrm{HbAlc})^{2}$.

All patients were initially submitted to examination 
to verify the clinical periodontal parameters (plaque index, probing bleeding, probing depth, clinical attachment level, and gingival recession) and pulp sensitivity testing. The study included patients who presented periodontal pockets involving the apical region of the tooth and pulp necrosis (periodontal endodontic lesion). Exclusion criteria were: use of antibiotics in the last six months, pregnancy, smoking, other systemic diseases, clinical signs of oral candidiasis, and patients who did not sign a free and clarified consent term.

\section{Sample collection}

The teeth were isolated with a rubber dam isolation. The crown and surrounding structures were disinfected with $5.25 \%$ sodium hypochlorite, and neutralized with $5 \%$ sodium thiosulfate. The sterility of the external surfaces of the crown was checked by taking a swab sample from the crown surface and streaking it on blood agar plates, which were then incubated both aerobically and anaerobically. The preparation of the access cavity was made using a sterile diamond drill speed, without the use of water spray, but with manual irrigation with sterile saline. Before entering the pulp chamber, the access cavity was again disinfected according to the protocol described above. The sterility of the internal surface of the access cavity was checked as previously described, and all procedures were performed aseptically. Sampling of the periodontal pocket was made at the deepest site through three sterile paper points, inserted one by one for one minute. Prior to periodontal sampling, all participants were requested to rinse their mouth with $10 \mathrm{ml}$ of $0.12 \%$ chlorhexidine gluconate solution (Periogard $^{\circledR}$ - Colgate-Palmolive Company, São Paulo, SP, Brazil), and the local area was dried and isolated with cotton rolls. Material collected from the periodontal pocket and the root canal was inoculated in Eppendorf tubes containing $1 \mathrm{ml}$ of reduced transport fluid (RTF). Subsequently, samples from each site were diluted and plated on the medium Saboraund Dextrose Agar plus Chloramphenicol and chromogenic medium (CHROMagar Candida ${ }^{\circledR}$, BioMerieux, Rio de Janeiro, $\mathrm{RJ}$, Brazil) and incubated at $37^{\circ} \mathrm{C}$ for $48 \mathrm{~h}$ in a reduced oxygen atmosphere (10\% $\mathrm{CO}_{2}$ and $90 \%$ air). The green colonies that grew on CHROMagar plates were chosen at random and stored in glycerol at $20^{\circ} \mathrm{C}$ for later identification by PCR.

\section{Molecular characterization of the species}

Fifty $\mathrm{ml}$ of Sabouraud medium were inoculated with conidia and incubated for $72 \mathrm{~h}$ at $300^{\circ} \mathrm{C}$. Mycelium was transferred to a $50 \mathrm{ml}$ polypropylene screw-capped bottle containing six glass beads ( $4 \mathrm{~mm}$ in diameter). The tube was immersed in liquid nitrogen for $10 \mathrm{~s}$ and stirred vigorously with a vortex mixer for $20 \mathrm{~s}$. Then, $2 \mathrm{ml}$ of DNA extraction buffer and $0.5 \mathrm{mg}$ per $\mathrm{ml}$ proteinase $\mathrm{K}$ (Sigma Chemical Co., St. Louis, MO, USA) were added, and the mixture was allowed to thaw. For the next step, the mixture was incubated for $2 \mathrm{~h}$ at $55^{\circ} \mathrm{C}$. Proteinase $\mathrm{K}$ was inactivated by heating the mixture at $950^{\circ} \mathrm{C}$ for $10 \mathrm{~min}$. A volume of $0.7 \mathrm{ml}$ of the mixture was transferred to a $1.5 \mathrm{ml}$ microfuge tube and an equal volume of phenol-chloroform ( $1: 1$ ) was added. The mixture was centrifuged at $10.000 x$ $\mathrm{g}$ for $5 \mathrm{~min}$ at $40^{\circ} \mathrm{C}$. Supernatant was transferred to a new tube and the same procedure was repeated using chloroform isoamyl alcohol (24:1). DNA was precipitated with 2 volumes of ethanol at $-200^{\circ} \mathrm{C}$ and centrifuged at $12.000 \times \mathrm{g}$ for $20 \mathrm{~min}$ at $40^{\circ} \mathrm{C}$. The pellet was allowed to dry. After washing with $70 \%$ ethanol at $40^{\circ} \mathrm{C}$, the extracted DNA was dissolved in $50 \mu \mathrm{l}$ of distilled water and $5 \mu \mathrm{l}$ of suspension and was used for PCR.

\section{Polymerase chain reaction (PCR)}

PCR reactions were standardized for each primer, using genomic DNA strains as a positive control. PCR reaction with DNA was performed for each universal primer to verify the presence of DNA as C. albicans (Forward: 5 '-ACT GCT CAA ACC ATC TCT GG-3 ‘ and Reverse: 5 ' -CAC AAG GCA AAT GAA GGA AT-3; with fragment size of $472 \mathrm{bp})^{19}$, and sterile distilled water was used as a negative control. Amplification was performed in T100 Thermal Cycler (PowerPac Basic, Bio-Rad Laboratories LTDA, Santo Amaro, SP, Brazil), programmed according to the following steps: predenaturation $\left(94^{\circ} \mathrm{C} / 5 \mathrm{~min}, 30 \mathrm{cycles}\right)$, denaturation $\left(94^{\circ} \mathrm{C} / 30 \mathrm{~s}\right.$ ), annealing ( TaoC calculated/30 s), and extension $\left(72^{\circ} \mathrm{C} / 1 \mathrm{~min} 30 \mathrm{~s}\right)$. Final extension was performed at $72^{\circ} \mathrm{C}$ for $4 \min ^{20}$

\section{Electrophoresis of amplification product}

After amplification, an analiquot of $2 \mu \mathrm{l}$ race marker "Low DNA Mass Ladder" or "123 ladder (I nvitrogen)" was added along with an equal volume of glycerol race containing dye [bromophenol blue $0.25 \%(w / v)$, xylenes cyanol FF $0.25 \%$ (w/v), 30\% glycerol (w/v) in 
water], and the total volume was applied to a channel of the gel. An aliquot of $10 \mu \mathrm{l}$ of PCR reaction product was added to the DNA $5 \mu \mathrm{l}$ at a time separately from the running dye. Dilutions were applied on different channels and subjected to electrophoresis (PowerPac Basic, Bio-Rad Laboratories LTDA, Santo Amaro, SP, Brazil) in agarose gel at $1.5 \%(\mathrm{w} / \mathrm{v})$ in TAE $1 \mathrm{X}$ buffer (Tris-acetate, $40 \mathrm{mM}$ EDTA 1 mM, pH 8.0) at $90 \mathrm{~V}$ for 90 minutes. The gel was subsequently treated with ethidium bromide at $0.5 \mu \mathrm{l} / \mathrm{ml}$ and DNA was visualized with the aid of an ultraviolet transilluminator (UV) and photographed with the aid of an automatic detection and image analysis system (Gel Doc XR + System with ImageLab Software, Bio-Rad Laboratories LTDA, Santo Amaro, SP, Brazil).

\section{Proteinase and phospholipase activity determination}

All isolates of C. albicans were tested in triplicate, for three separate experiments, to verify the enzymatic activity of proteinases (SAPS) and phospholipases ${ }^{16,28}$. The proteinase culture medium was BSA (bovine serum albumin) and the phospholipase culture medium consisted of enriched egg yolk. Plates were incubated at $37^{\circ} \mathrm{C}$ in a reduced oxygen atmosphere or in anaerobic conditions for $48 \mathrm{~h}$ to examine the proteases and for $72 \mathrm{~h}$ to examine phospholipases. Enzymatic activity was determined by the formation of a halo around the colony of yeast. The halo was measured in terms of the relationship between the diameter of the colony and the overall diameter of the colony plus the precipitation zone ( $\mathrm{Pz})$, according to the method described by Price, Wilkinson and Gentry ${ }^{16}$ (1982).

\section{Determination of hemolysin activity}

Hemolysin activity was evaluated for all the isolates of C. albicans using blood agar medium ${ }^{25}$. Samples were grown on SDA for $24 \mathrm{~h}$ and incubated at $37^{\circ} \mathrm{C}$ in either a reduced oxygen atmosphere or anaerobic conditions for 48 and 72 h, respectively. An additional $10 \mu \mathrm{l}$ of saline without yeast was placed on the same plate. The reference strain of $C$. albicans (ATCC 90.028) was used as a positive control. In addition, standard strains of Staphylococcus aureus (ATCC 10.832) and Streptococcus mutans (UA159), which repectively induce hemolysis beta and alpha, were used as a positive control. Gamma-hemolytic samples produce no halo, alpha-hemolytic samples produce a green halo, and beta-hemolytic samples produce a yellow halo. Assays were also conducted in triplicate.

\section{Cellular superficial hydrophobicity assay (CSH)}

This assay was performed according to Rodrigues, et al. ${ }^{19}$ (1999) for all isolates of C. albicans, in two independent experiments. Fifty $\mathrm{ml}$ of Sabouraud dextrose broth (SDB, Disco Laboratories Detroit, MI, USA) were inoculated with yeast cells and incubated overnight at $37^{\circ} \mathrm{C}$ in a $10 \%$ reduced oxygen environment or in anaerobic conditions. Yeast cells were harvested and washed twice in phosphate buffer $(\mathrm{pH} 8.0)$. Yeast slurry was prepared in the same buffer to reach an optical density $[(A 0) 0.4-0.6$ at $600 \mathrm{~nm}]$, and $150 \mu \mathrm{l}$ of hexadecane was added to 3 $\mathrm{ml}$ of this yeast suspension. After 10 min incubation at $30^{\circ} \mathrm{C}$, tubes were agitated by vortexing twice for 30 seconds. After allowing phase separation for 30 min, the optical density of the lower aqueous phase (A1) was measured and compared with the optical density obtained before the mixing step (A0). The percentage of cells in the hexadecane layer (adherent cells) was used to estimate the hydrophobicity, using the following formula: $\% \mathrm{H}=\mathrm{A} 0-\mathrm{A} 1 / \mathrm{AO} \times 100 \%$.

\section{Statistical analysis}

Data distributions were expressed as means, standard deviations (SD), ranges and percentages, as appropriate. The results obtained for the tested virulence factors were analyzed according to the atmospheric condition, using Chi-square and Wilcoxon nonparametric tests. Differences were considered statistically significant when $p<0.05$. All data were analyzed using the Statistical Package for Social Sciences (SPSS, Chicago, IL) version 16.0.

\section{Results}

Diabetic and control groups were homogenous. Mean and standard deviation were obtained to establish comparisons between groups (Table 1 ).

Of the 60 samples collected (Figures 1 and 2) - 30 from periodontal pockets and 30 from root canals - $24(40 \%)$ showed a positive culture for C. albicans. Nineteen of these 24 were from patients with diabetes mellitus and five from normoglycemics, corresponding to $79.2 \%$ and $20.8 \%$ of the collected samples, respectively. Of the 30 samples collected from periodontal pockets, $13(43.3 \%)$ had a positive culture, 10 belonged to diabetic patients (77\%) and 3 were from normoglycemics (23\%). Of the 11 positive 
samples from root canals, 9 were from patients with diabetes mellitus ( $82 \%$ ) and 2 from normoglycemic patients $(18 \%)$.

C. albicans strains were found more often in diabetic patients. There was a statistical difference for the number of strains isolated from periodontal pockets and root canals of diabetic and normoglycemic patients when analyzed by Chi-square test $(p<0.05)$.

Strains of C. albicans showed an increased virulence in diabetic patients (Table 2), demonstrating a statistically significant difference $(p=0.001)$ after applying the Wilcoxon test. Hemolysin activity was positive for both groups in both atmospheres, but was not significantly different among test groups in both atmospheres.

Production of proteinase presented $\mathrm{Pz}<0.63$ of $100 \%$ in $\mathrm{G} 1$ and $72 \%$ in $\mathrm{G} 2$ in redox and negative $(\mathrm{Pz}=1)$, under anaerobic conditions in both groups. Phospholipase activity was higher in samples from G1 in redox and anaerobic conditions. Hydrophobicity of the strains of G1 indicated $16.4 \%$ with low, $19.3 \%$ with moderate and $64.3 \%$ with high hydrophobicity in redox. In G2, 42.2\% showed low, 39.8\% moderate, $18 \%$ high hydrophobicity in redox. Anaerobically, G1 presented $15.2 \%$ with low, $12.8 \%$ with moderate and $72 \%$ with high hydrophobicity; G2, showed $33.6 \%$

Table 1- Main characteristics of the subjects studied

\begin{tabular}{|c|c|c|c|c|c|c|c|c|}
\hline & \multicolumn{4}{|c|}{ Diabetics $(n=15)$} & \multicolumn{4}{|c|}{ Controls $(n=15)$} \\
\hline & Min & Max & Mean & SD & Min & Max & Mean & SD \\
\hline age & 38 & 69 & 52 & 10.23 & 39 & 70 & 53.3 & 12.12 \\
\hline PD & 4 & 14 & 8.2 & 3 & 4 & 14 & 8.3 & 3.2 \\
\hline CAL & 9 & 18 & 13.5 & 3.34 & 7 & 24 & 12.9 & 4.44 \\
\hline HBA1C & 6.2 & 11.3 & 8.5 & 1.78 & 5 & 5 & 5 & 0 \\
\hline \multirow[t]{3}{*}{ GLIC_L } & 27 & 295.8 & 190.3 & 71.64 & 74 & 90 & 84.5 & 5.01 \\
\hline & \multicolumn{4}{|c|}{ Diabetics $(n=15)$} & \multicolumn{4}{|c|}{ Controls $(n=15)$} \\
\hline & \multicolumn{4}{|c|}{$\mathrm{n}(\%)$} & & \multicolumn{3}{|c|}{$\mathrm{n}(\%)$} \\
\hline \multirow[t]{2}{*}{ Sex } & & male & $6(40)$ & & & male & $5(33.3)$ & \\
\hline & & female & $9(60)$ & & & female & $10(66.7)$ & \\
\hline \multicolumn{9}{|l|}{$\mathrm{PI}$} \\
\hline & & no & 0 & & & no & $1(6.7)$ & \\
\hline & & yes & $15(100)$ & & & yes & 14 (93.3) & \\
\hline \multicolumn{9}{|l|}{$\mathrm{Gl}$} \\
\hline & & no & $1(6.7)$ & & & no & $2(13.3)$ & \\
\hline & & yes & $14(93.3)$ & & & yes & $13(86.7)$ & \\
\hline
\end{tabular}

PD, probing depth; CAL, clinical attachment loss; HBA1C, glycosylated hemoglobin concentrations; GLIC, plasma glucose level; PI, plaque index; $\mathrm{Gl}$, gengival index

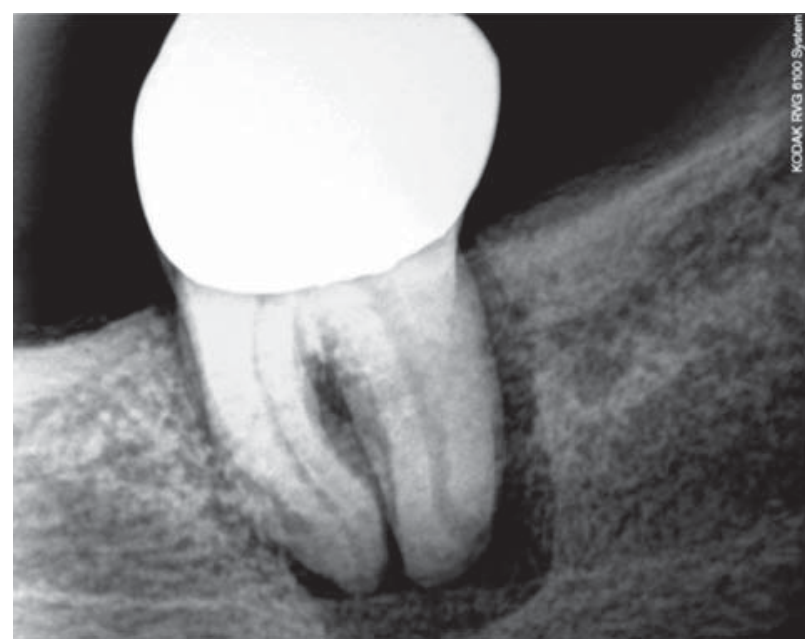

Figure 1- Radiographic image of tooth with periodontal endodontic lesion

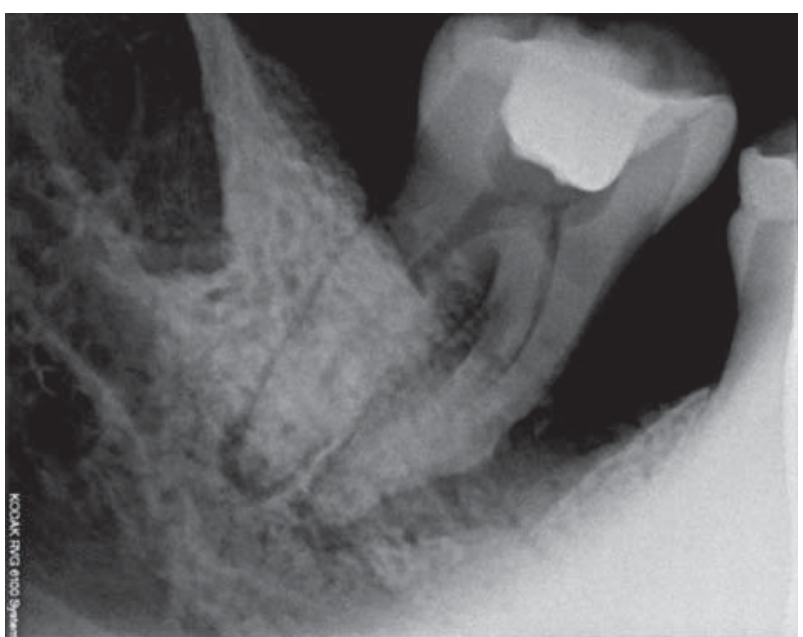

Figure 2- Radiographic image of tooth with periodontal endodontic lesion 
Table 2- Virulence of Candida albicans strains

\begin{tabular}{|c|c|c|c|c|c|c|}
\hline \multirow[t]{2}{*}{ Virulence of Candida albicans strains } & \multicolumn{3}{|c|}{ Diabetic (G1) } & \multicolumn{3}{|c|}{ Normoglycemic (G2) } \\
\hline & & Redox & Anaerobic & & Redox & Anaerobic \\
\hline & Negative $(P z=1)$ & 0 & $100 \%$ & Negative $(P z=1)$ & $2 \%$ & $100 \%$ \\
\hline \multirow[t]{4}{*}{ PROTEINASE } & Positive $(P z=1-0.63)$ & 0 & 0 & Positive $(P z=1-0.63)$ & $6 \%$ & 0 \\
\hline & $\begin{array}{l}\text { Strongly Positive } \\
(\mathrm{Pz}<0.63)\end{array}$ & $100 \%$ & 0 & $\begin{array}{l}\text { Strongly Positive } \\
(\mathrm{Pz}<0.63)\end{array}$ & $72 \%$ & 0 \\
\hline & & Redox & Anaerobic & & Redox & Anaerobic \\
\hline & Negative $(P z=1)$ & $18.5 \%$ & $51.2 \%$ & Negative $(P z=1)$ & $0.3 \%$ & $100 \%$ \\
\hline \multirow[t]{4}{*}{ PHOSPHOLIPASE } & Positive (Pz=1 - 0.63) & $28.3 \%$ & $15.3 \%$ & Positive (Pz=1 - 0.63) & $6.4 \%$ & 0 \\
\hline & $\begin{array}{l}\text { Strongly Positive } \\
(\mathrm{Pz}<0.63)\end{array}$ & $53.2 \%$ & $33.5 \%$ & $\begin{array}{l}\text { Strongly Positive } \\
(\mathrm{Pz}<0.63)\end{array}$ & $23.3 \%$ & 0 \\
\hline & & Redox & Anaerobic & & Redox & Anaerobic \\
\hline & Alpha & $84.8 \%$ & $80.4 \%$ & Alpha & $81 \%$ & $70.3 \%$ \\
\hline \multirow[t]{4}{*}{ HEMOLYSIN } & Beta & $15.2 \%$ & $19.6 \%$ & Beta & $19 \%$ & $29.7 \%$ \\
\hline & Gama & 0 & 0 & Gama & 0 & 0 \\
\hline & & Redox & Anaerobic & & Redox & Anaerobic \\
\hline & Low & $16.4 \%$ & $15.2 \%$ & Low & $42.2 \%$ & $33.6 \%$ \\
\hline \multirow[t]{2}{*}{ HYDROPHOBICITY } & Moderate & $19.3 \%$ & $12.8 \%$ & Moderate & $39.8 \%$ & $28.8 \%$ \\
\hline & High & $64.3 \%$ & $72 \%$ & High & $18 \%$ & $37.6 \%$ \\
\hline
\end{tabular}

with low, $28.8 \%$ with moderate and $37.6 \%$ with high hydrophobicity. There was statistical difference in the number of positive cultures between $\mathrm{Gl}$ and G2 $(p<0.05)$ with predominance in $G 1$. There was statistical difference for all virulence factors, except hemolysis $(p=0.001)$.

\section{Discussion}

Fungi are considered normal inhabitants of the oral cavity, however, it may cause diseases when local or systemic factors such as diabetes mellitus predispose the individual. Premkumar, Ramani and Chandrasekar ${ }^{15}$ (2014) showed that patients with diabetes mellitus have a significantly increased prevalence of $C$. albicans strains in the oral cavity. The prevalence rate of the Candida species in diabetics was $87.5 \%$, whereas in the control subjects it was $50 \%$ (collected by oral rinse method). In the present study, $40 \%$ showed a positive culture for C. albicans, $79.2 \%$ were from patients with diabetes mellitus, and $20.8 \%$ from normoglycemics. This discrepancy may be explained by the fact that the samples in this study were collected from periodontal pockets and root canals.

Candida albicans is the fungal species most commonly detected in the oral cavity, both in healthy individuals and in individuals with systemic involvement ${ }^{23}$. It is also the most often isolated fungal species in chronic periodontitis ${ }^{19,21}$ and infected root canals $^{22,23}$. Kumar, Muralidhar and Banerjee ${ }^{11}$ (2015) isolated C. albicans in $21 \%$ of samples from patients with periodontal disease. Urzua, et al. ${ }^{26}$ (2008) isolated the fungus in $69.2 \%$ of periodontal sites of chronic periodontitis. In the present study, C. albicans was isolated in $43.3 \%$ of the samples collected from the periodontal pockets. Different results could be related to either different collection sites or systemic factors, as these samples were composed by both diabetic and normoglycemic patients.

This higher incidence of $\mathrm{C}$. albicans in diabetic patients may be explained by the alteration of the normal oral flora in response to endocrine disorders of diabetes mellitus. Moreover, it may be attributed to increased adhesion of fungi in epithelial cells facilitated by increased glucose content in saliva, genetic susceptibility to infection, changes in defense mechanisms, and changes in local factors, including disadvantaged blood support ${ }^{1}$.

However, BremenKamp, et al. ${ }^{4}$ (2011) showed no significant difference in the prevalence of $C$. albicans between diabetic and normoglycemic patients. This contradiction with our results can be attributed to the fact that patients included in the study cited above beared glycated haemoglobin levels lower or equal to $9 \%$, whereas in the present study patients presented glycated hemoglobin levels ranging from $6.2 \%$ to $11.3 \%$. Blood glucose levels have a positive 
relationship with increasing transport rate and cell density in diabetic patients ${ }^{3}$.

Virulence factors of the $\mathrm{C}$. albicans species may be involved in the pathogenesis of various oral diseases. However, few studies have investigated its role in host colonization and development of infections ${ }^{10}$.

In this study, it was observed that the fungi present in diabetic patients had proteinase, phospholipase, and hemolysin activity, and cell surface hydrophobicity in both tested environments. This is in line with the literature on this fungi's adaptive survival conditions ${ }^{12}$.

In the present investigation, proteinase expression was detected in $100 \%$ of the strains of C. albicans when incubated in a redox atmosphere. These results are similar to the findings of Sardi, et al. ${ }^{21}$ (2012), who found a high activity of proteinase in patients with type 2 diabetes mellitus.

Phospholipase activity on C. albicans strains not only determine commensal colonization, but also provide potential pathogenic yeasts ${ }^{11}$. Studies have reported that $30-100 \%$ of the oral C. albicans isolates produce phospholipases, with varying degrees of enzyme activity ${ }^{25}$. In this study, this enzyme was detected in $53.2 \%$ of Candida albicans strains when incubated in a reduced oxygen atmosphere. The anaerobic condition showed $33.5 \%$ activity.

Our analysis showed no statistically significant difference for the hemolysin activity in diabetic and normoglycemic patients in both tested atmospheres. Manns, Mosser and Buckley ${ }^{13}$ (1994) determined the conditions under which $\mathrm{C}$. albicans can show hemolytic activity and found that hemolysis is not observed when glucose is not available in the culture medium.

The cell surface hydrophobicity was evaluated under anaerobic and redox conditions, with the results indicating greater hydrophobicity in anaerobic conditions. The results of this study indicated that $72 \%$ of the isolates were highly hydrophobic under anaerobic atmospheres and $64.3 \%$ under the redox atmospheres. Hydrophobic interactions may be important in the tissue invasion of the mycelia phase of yeast cells ${ }^{21}$.

Our findings follow the same trend of the authors Siqueira and $\operatorname{Sen}^{23}$ (2004), and Gomes, et al. ${ }^{8}$ (2010), who investigated the importance of filamentous fungi in root canals of teeth with pulp necrosis and periradicular lesions, which may participate in the etiology of periradicular diseases.

The duration of diabetes and quality of metabolic control are related to the development of diabetic complications. Poorly controlled diabetes has been associated with high incidence of Candida infections and such situation may suggest difficulty in treatment ${ }^{4}$. C. albicans seems to be present more frequently in the root canals of obturated teeth in which treatment has failed ${ }^{22}$.

\section{Conclusion}

The prevalence of Candida albicans was higher in patients with diabetes mellitus in samples collected from periodontal pockets and root canals. Strains of Candida albicans showed increased virulence in diabetic patients compared to normoglycemic patients. The production of proteinase and phospholipase activity were higher in diabetic patients when analyzed in redox. Hydrophobicity of the strains were higher in diabetic patients under anaerobic conditions. However, hemolytic activity was positive for both groups in both atmospheres.

\section{Acknowledgements}

The authors deny any conflict of interest related to this study. We thank FAPERJ - Rio de J aneiro Research Foundation (RJ, Brazil) for financial support (Process number E.26/111.809/2012).

\section{References}

1- Al-Fouzan KS. A new classification of endodontic-periodontal lesions. Int J Dent. 2014;2014:919173.

2- American Diabetes Association. Standards of medical care in diabetes. Diabetes Care. 2016: 39(Supp 1):S1-112.

3- Belazi M, Velegraki A, Fleva A, Gidarakou I, Papanaum L, Baka D, et al. Candidal overgrowth in diabetic patients: potential predisposing factors. Mycoses. 2005;48(3): 192-6.

4- Bremenkamp RM, Caris AR, Jorge AO, Back-Brito GN, Mota AJ Balducci I, et al. Prevalence and antifungal resistance profile of Candida spp. oral isolates from patients with type 1 and 2 diabetes mellitus. Arch Oral Biol. 2011;56(6):549-55.

5- Canabarro A, Valle C, Farias MR, Santos FB, Lazera M, Wanke B. Association of subgingival colonization of Candida albicans and other yeasts with severity of chronic periodontitis. J Periodont Res. 2013; 48(4): 428-32.

6- Egan MW, Spratt DA, Ng YL, Lam JM, Moles DR, Gulabivala K. Prevalence of yeasts in saliva and root canals of teeth associated with apical periodontitis. Int Endod J. 2002; 35(4):321-9.

7- Gomes BP, Berber VB, Kokaras AS, Chen T, Paster BJ. Microbiomes of endodontic-periodontal lesions before and after chemomechanical preparation. J Endod. 2015;41(12): 1975-84. 
8- Gomes C, Fidel S, Fidel R, Sarquis MI. Isolation and taxonomy of filamentous fungi in endodontic infections. J Endod. 2010; 36(4):626-9. 9- Kerekes K, Olsen I. Similarities in the microfloras of root canals and deep periodontal pockets. Endod Dent Traumatol. 1990;6(1):1-5. 10- Koga-Ito CY, Lyon JP, Vidotto V, Resende MA. Virulence factors and antifungal susceptibility of Candida albicans isolates from oral candidosis patients and control individuals. Mycopathologia. 2006; 161(4): 219-23.

11- Kumar DA, Muralidhar S, Banerjee U, Khan LA. Antifungal resistance patterns, virulence attributes and spectrum of oral Candida species in patients with periodontal disease. Br Microbiol Res J. 2015; 5(1):68-75. 12- Madigan MT, Martinko JM. Growth of bacteria populations. In: Madigan MT, Martinko JT, Bender KS. Brock biology of microorganisms. San Francisco: Pearson Publishers; 2006. p.140-2.

13- Manns J M, Mosser DM, Buckley HR. Production of a hemolytic factor by Candida albicans. Infect Immun. 1994;62(11):5154-6.

14- Mealey BL, Oates TW, American Academy of Periodontology. Diabetes mellitus and periodontal diseases. J Periodontol. 2006; 77(8): 1289-303. 15- Premkumar J, Ramani P, Chandrasekar T, Natesan A, Premkumar P. Detection of species diversity in oral Candida colonization and antifungal susceptibility among non-oral habit adult diabetic patients. J Nat Sci Biol Med. 2014;5(1):148-54.

16- Price MF, Wilkinson ID, Gentry LO. Plate method for detection of phospholipase activity in Candida albicans. Sabouraudia. 1982;20(1): 714

17- Ramanan N, Wang Y. A high-affinity iron permease essential for Candida albicans virulence. Science. 2000;288(5468): 1062-4.

18- Reynaud AH, Nygaard-Østby B, Bøygard GK, Eribe ER, Olsen I, Gjermo P. Yeasts in periodontal pockets. J Clin Periodontol. 2001;28(9):860-4.

19- Rodrigues AG, Mårdh PA, Pina-Vaz C, Martinez-de-Oliveira J, Fonseca AF. Germ tube formation changes surface hydrophobicity of Candida cells. Infect Dis Obstet Gynecol. 1999; 7(5):222-6.
20- Sardi JC, Duque C, Camargo GA, Höfling JF, Gonçalves RB. Periodontal conditions and prevalence of putative periodontopathogens and Candida spp. in insulin-dependent type 2 diabetic and non-diabetic patients with chronic periodontitis - a pilot study. Arch Oral Biol. 2011; 56(10): 1098-105.

21- Sardi JC, Duque C, Höfling JF, Gonçalves RB. Genetic and phenotypic evaluation of Candida albicans strains isolated from subgingival biofilm of diabetic patients with chronic periodontitis. Med Mycol. 2012; 50(5): 467-75.

22- Siqueira JF. Endodontic infections: concepts, paradigms, and perspectives. Oral Surg Oral Med Oral Pathol Oral Radiol Endod. 2002; 94(3): 281-93.

23- Siqueira JF J r, Sen BH. Fungi in endodontic infections. Oral Surg Oral Med Oral Pathol Oral Radiol Endod. 2004;97(5):632-41.

24- Song X, Eribe ER, Sun J, Hansen BF, Olsen I. Genetic relatedness of oral yeasts within and between patients with marginal periodontitis and subjects with oral health. J Periodont Res. 2005;40(6):446-52. 25- Tsang C, Chu FC, Leung WK, J in LJ, Samaranayke LP, Siu SC. Phospholipase, proteinase and haemolytic activities of Candida albicans isolated from oral cavities of patients with type 2 diabetes mellitus. J Med Microbiol. 2007; 56(10): 1393-8.

26- Urzúa B, Hermosilla G, Gamonal J, Morales-Bozo I, Canals M, Barahona S, et al. Yeast diversity in the oral microbiota of subjects with periodontitis: Candida albicans and Candida dubliniensis colonize the periodontal pockets. Med Mycol. 2008;46(8): 783-93.

27- Wang CH, Chueh LH, Chen SC, Feng YC, Hsiao CK, Chiang CP. Impact of diabetes mellitus, hypertension, and coronary artery disease on tooth extraction after nonsurgical endodontic treatment. J Endod. $2011 ; 37(1): 1-5$.

28- Willis AM, Coulter WA, Fulton CR, Hayes JR, Bell PM, Lamey PJ. The influence of antifungal drugs on virulence properties of Candida albicans in patients with diabetes mellitus. Oral Surg Oral Med Oral Pathol Oral Radiol Endod. 2001;91(3):317-21. 